\title{
Rehabilitation of the North End Box Cut dump at Tom Price mine operation: a legacy management case study
}

\author{
T Worthington Rio Tinto Iron Ore, Australia \\ R Green Rio Tinto Iron Ore, Australia \\ CL Latham Rio Tinto Iron Ore, Australia \\ B Yaqub Rio Tinto Iron Ore, Australia
}

\begin{abstract}
The North End Box CUt (NEBC) waste dump at Rio Tinto's Tom Price iron ore operation is an historic waste dump that contains an estimated 2.6 Mt of potentially acid forming (PAF) shale material. The dump is 75 ha in size and is positioned on the edge of the site's current operational footprint.

Construction of the NEBC waste dump began in the 1990s, and the PAF material was encapsulated within the dump. However, the dump does not meet Rio Tinto's current standards for PAF material management or landform design, which were first developed in 1999 but have been updated since to reflect changes in industry knowledge on PAF material and its management. In particular, there is limited information on the position of the PAF cells within the NEBC waste dump, and the risk of surface exposure of PAF material during rehabilitation earthworks is considered high.

The dump is scheduled for rehabilitation commencing in 2019 and presents significant challenges regarding the application of current best practice standards to a legacy waste dump. The current approach for rehabilitating the NEBC waste dump involves significant reshaping works to achieve a stable landform design, followed by encapsulation of PAF material under all batters and berm surfaces with inert waste to minimise the risk of water and oxygen ingress into the dump. This approach necessitates the movement of millions of cubic metres of inert mineral waste to achieve the final design and to manage the potential for acid and/or neutral mine drainage. To achieve the rehabilitation design, the rehabilitation requirements have been integrated into the site mine plan, allowing the project to capitalise on scheduled ex-pit waste movements. This paper reviews the challenges that have arisen throughout the project and highlights the opportunities that can present when rehabilitation activities are integrated into the mine plan.
\end{abstract}

Keywords: legacy, rehabilitation, potentially acid forming, black shale, waste dump

\section{Introduction}

The North End Box Cut (NEBC) waste dump is located at Rio Tinto's Tom Price mine site in the Pilbara region of Western Australia (Figure 1). Tom Price commenced operations in 1966 and was the first iron ore mine in the Pilbara region. The mine is an open cut operation, utilising conventional drill-and-blast and load-and-haul mining methods. Ore is processed onsite before being transported via rail to either the Dampier or Cape Lambert ports for shipping. The Tom Price mine is owned and operated by Hamersley Iron Pty Ltd, which is wholly owned by Rio Tinto Limited and hereafter referred to as Rio Tinto.

The climate in the Tom Price area can be characterised as arid-tropical with two distinct seasons: hot wet summers and cooler dry winters, meaning daily maxima temperatures range from $38^{\circ} \mathrm{C}$ in summer to $23^{\circ} \mathrm{C}$ in winter. Precipitation is driven by summer cyclonic activity, with the months of August to November having the lowest average rainfall, and December to March the highest average rainfall. Annual rainfall ( $399 \mathrm{~mm} /$ year) in the region is highly variable, with mean pan evaporation rates $(3,200-3,600 \mathrm{~mm} /$ year) in the region greatly exceeding rainfall. 
The NEBC waste dump is an historic waste landform at the Tom Price mine. It is 75 ha with a maximum height of ca. $55 \mathrm{~m}$ (Figure 2). Construction of the NEBC dump began in 1994, and it was used for disposal of unoxidised Mount McRae shale material from nearby pits. This waste rock is commonly referred to as black shale and is known to be potentially acid forming (PAF). The presence of reactive black shale waste represents a rehabilitation concern due to its potential to generate acid and metalliferous drainage (AMD), which may be triggered by the presence of sulphides, in particular pyrite $\left(\mathrm{FeS}_{2}\right)$ within the waste material. Most recently, the NEBC dump was used for disposal of inert, non-reactive waste that was deposited above the stored PAF material.

Dumping of the black shale material in the NEBC dump was carried out according to industry best practice at the time, which involved covering the black shale material with inert waste. However, no as-built survey data exists on the location of the black shale cells and some surface exposures have been previously identified on the dump slopes. The dump is estimated to hold $2.6 \mathrm{Mt}$ of black shale material (i.e. 9.5\% of the total material). All black shale is conservatively assigned as PAF waste and encapsulated, regardless of sulphur content. The average total sulphur concentration of the black shale from the various mine pits at Tom Price can range from 0.2 to $1.6 \%$.

In the late 1990s, rehabilitation was carried out on the northwest half of the NEBC dump. The success of this rehabilitation effort has been variable, with good vegetation establishment recorded in areas on top of the dump and parts of the upper batter, but with rehabilitation failing on the lower batter extents. The landform does not meet current landform design requirements, particularly with regards to slope length and surface water management, and a walkover of the lower batters in 2018 identified black shale material at the surface.

Groundwater quality has been monitored around the NEBC dump since 2001. There are currently four bores that are sampled every six months for water chemistry. No evidence of AMD has been detected within these bores. The $\mathrm{pH}$ is typically circum-neutral, and the groundwater is generally fresh (median TDS $580 \mathrm{mg} / \mathrm{L}$ ). Sulphate concentrations were generally low (median $35 \mathrm{mg} / \mathrm{L}$ ) and some alkalinity is present (median $370 \mathrm{mg} / \mathrm{L}$ ).

To manage the AMD risk associated with the PAF material, a $4 \mathrm{~m}$ store and release cover was installed, consisting of two lifts of $2 \mathrm{~m}$ each, on the highest bench of the dump (now 832 relative levels ( $R L$ )), in the southern section. Each lift was paddock dumped with non-acid forming material and levelled. The primary role of the store and release cover is to control the amount of water that infiltrates through the dump (Shurniak et al. 2012). During a construction inspection (and lysimeter installation) on the store and release cover, it was noticed that large boulders were present within the cover (Green 2012). Large boulders could promote preferential flow-through the cover and increase net percolation. The cover construction consequently ceased, and the remaining section of the cover was constructed with more appropriately graded material.

All areas of the NEBC waste dump now require rehabilitation earthworks to be carried out to ensure the PAF black shale material is adequately encapsulated, in line with Rio Tinto's current PAF management strategies, and to ensure the final landform meets current landform design criteria. This work is scheduled to commence in 2019. 


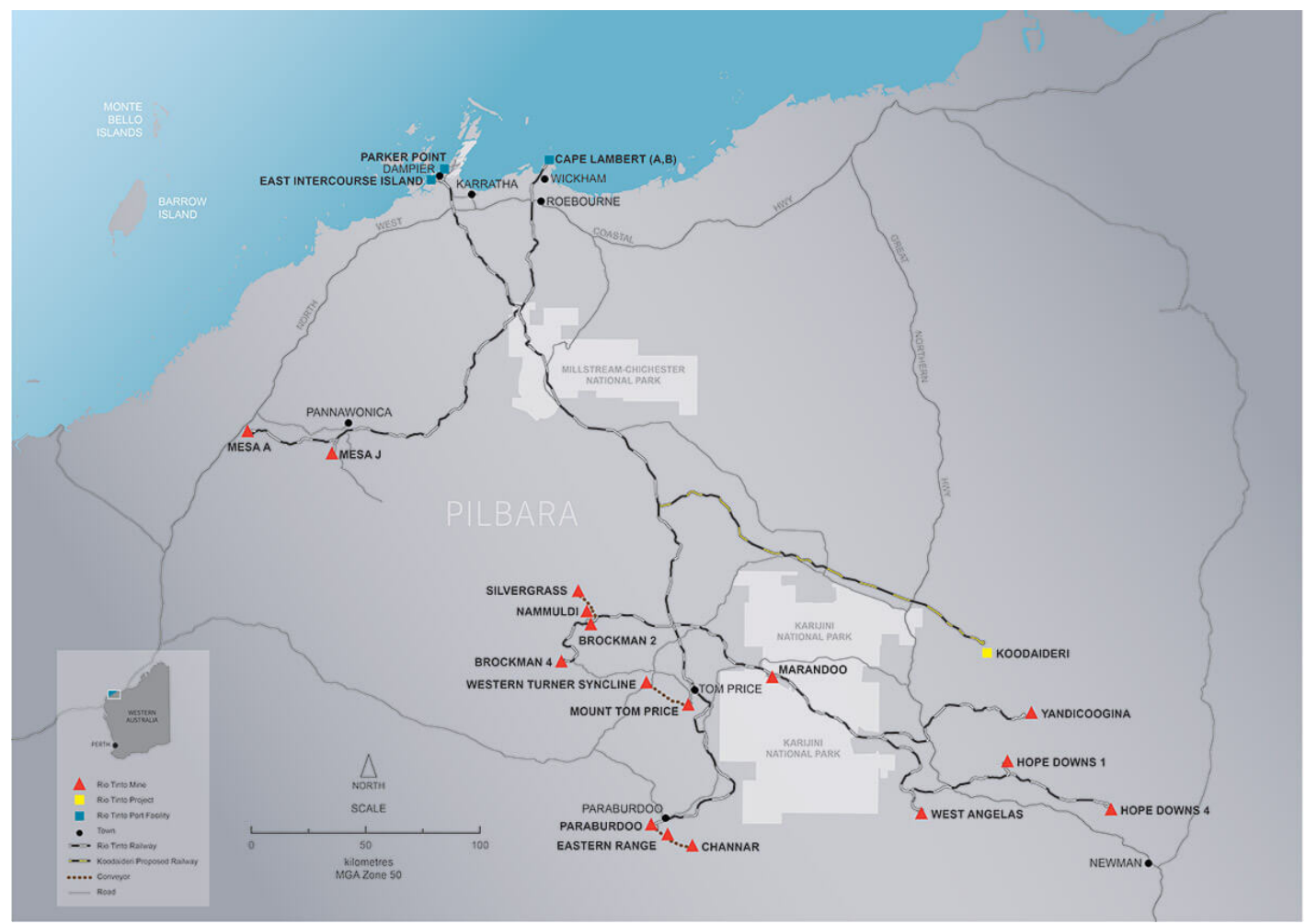

Figure 1 Rio Tinto Iron Ore operations in Western Australia

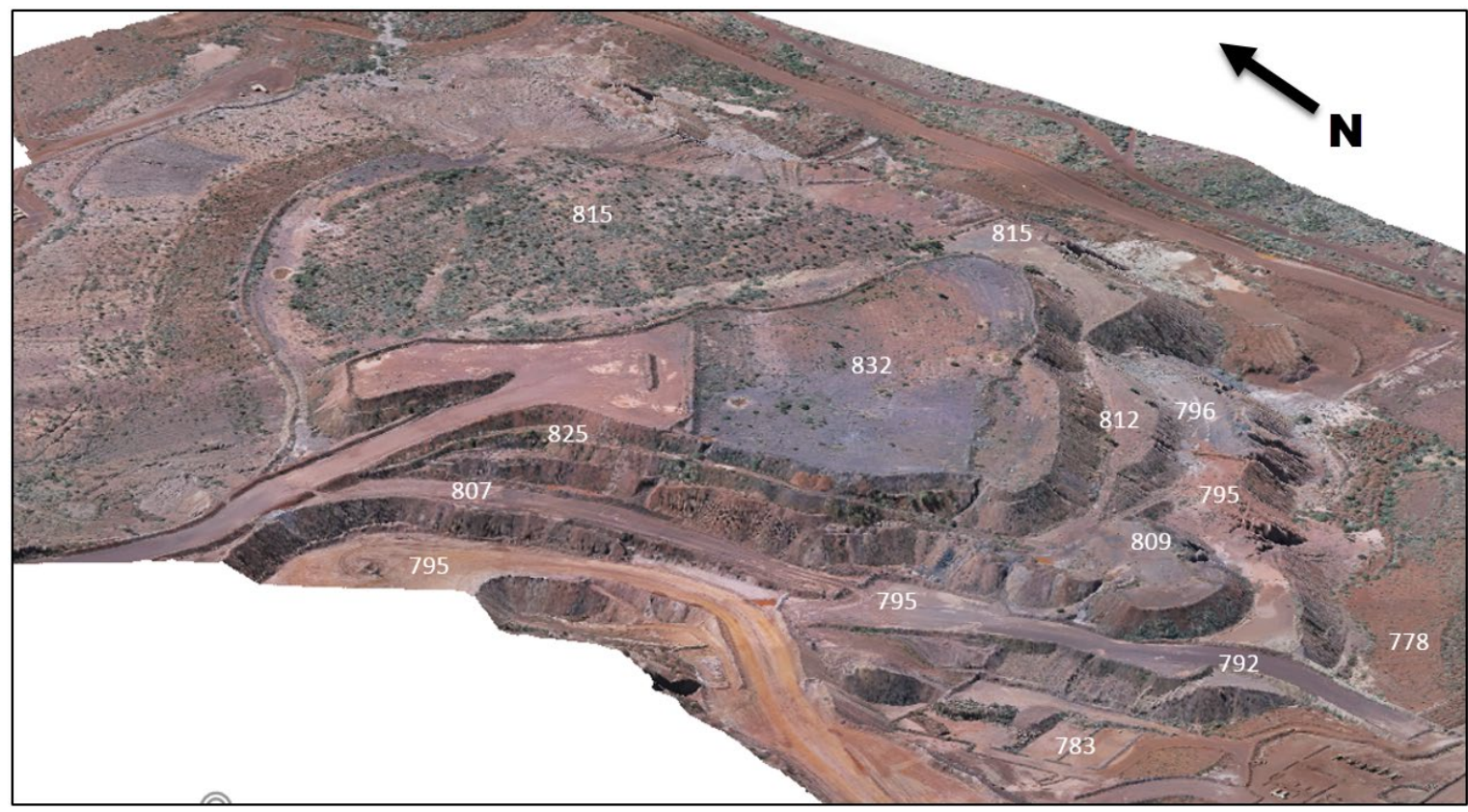

Figure 2 Aerial image of the North End Box Cut waste dump at Tom Price operation. Annotations indicate bench RL in metres

\section{$2 \quad$ Planning for rehabilitation of North End Box Cut waste dump}

\subsection{Development of a waste dump knowledge base}

Rehabilitation of the NEBC waste dump has been a long-term focus for Rio Tinto. Planning for the rehabilitation of the waste landform commenced a number of years ago; however, a lack of information on the internal placement of the PAF black shale material prevented the rehabilitation design from being 
finalised. Without sufficient information on the black shale location, the risk of exposure of the material during dump reshaping was considered high. To address this knowledge gap, 41 cores were drilled along the western edge of the NEBC dump to determine the depth of clean fill material present above the black shale waste. This drilling program identified seven locations out of 41 , all clustered around the outer western face, where additional cover would be required to be placed above the black shale material during rehabilitation works.

Subsequent to the drilling being completed, a detailed analysis of net acid generation potential, internal dump temperatures and intrinsic oxidation rates were undertaken every $2 \mathrm{~m}$ within the waste dump using three drill holes. This study demonstrated that there was no strong evidence of convective (driven by heat) or advective (driven by wind) gas transport within the dump. Diffusive gas transport is the major process. The oxygen concentration dropped to zero inside the reactive black shale layers and hence there are regions of black shale in the dump that are not oxidising.

A detailed review of rectified and non-rectified aerial photography from 1994 onwards was also conducted with black shale dumping locations mapped in GIS software package MapInfo, based on visual indicators (dark coloured waste). This work identified a number of areas where black shale is likely to have been dumped within the landform. However, definitive conclusions could not be made about black shale locations due to the similarity in colour between the PAF material and inert banded iron formation waste. The outcome of this review is presented in Figure 3, which shows areas of likely black shale deposition in the south of the dump. No black shale deposition in the northern section of the dump was evident during the aerial imagery review.

The following two limitations exist with this method:

1. Historic aerial images were taken on an irregular basis, ranging from once every few years to several times per year depending on business need. Therefore, the possibility exists for black shale to have been deposited and subsequently covered in the period between image capture.

2. The polygons generated show possible black shale locations but provide no guide to the depth of the material or the volume deposited.

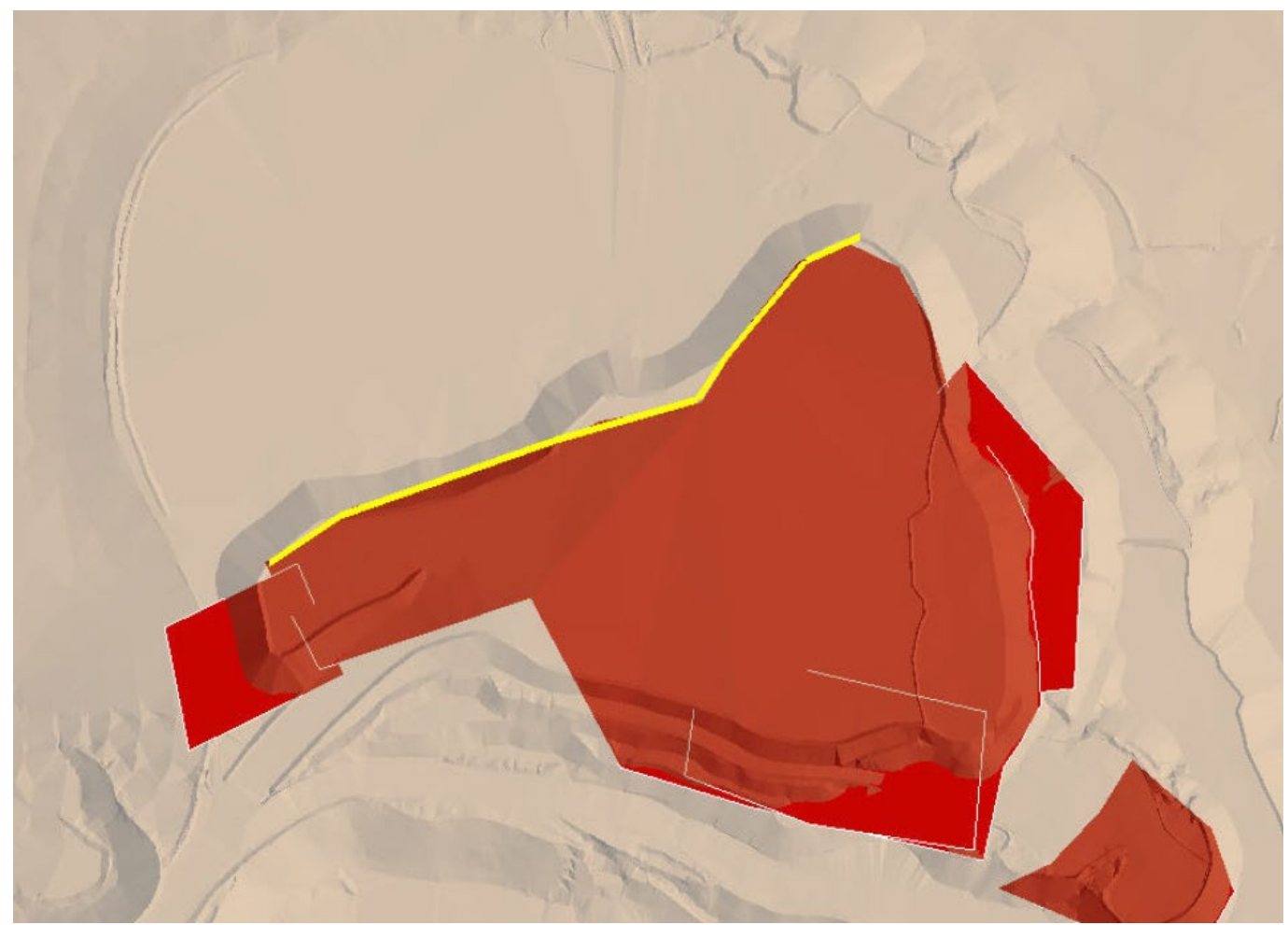

Figure 3 Areas of possible black shale deposition within the North End Box Cut waste dump (red shading) at Tom Price operations, based on a review of historic aerial imagery 
Following the aerial imagery review, a second drilling program was undertaken to confirm the presence/absence of black shale in the northern section of the dump. Six cores were drilled on the previously rehabilitated $815 \mathrm{RL}$. This drilling confirmed the presence of black shale in three of the six cores, but all black shale encountered was at depths $>5 \mathrm{~m}$. This depth of encapsulation meets Rio Tinto's current management strategy for black shale and indicated that no further cover was likely to be needed in this area.

In 2018, a walkover was conducted of the lower rehabilitation extents on the northern side of the dump, an area that had received little focus during previous investigations. This walkover was targeted at areas where aerial imagery showed dark surface staining and poor vegetation establishment. The walkover confirmed the presence of black shale material on the surface of the previously rehabilitated area.

Based on the information collated about the NEBC waste dump over many years, the following was concluded:

- Black shale was dumped in the southern extents of the dump, however the depth of cover above the shale is unknown. The volume of shale deposited in this area is also unknown.

- Black shale is buried beneath the $815 \mathrm{RL}$, but drilling suggests that the current depth of cover provides adequate encapsulation.

- Black shale exists at the surface on the northern batters, in the previously rehabilitated part of the dump.

- The store and release cover placed on the now $832 \mathrm{RL}$ in 2005 was partially constructed using inappropriately sized materials.

Based on the above, a rehabilitation design was required for NEBC waste dump that would manage the PAF black shale material but also meet Rio Tinto's current landform design criteria for rehabilitated waste dumps.

\subsection{Rehabilitation design development for North End Box Cut waste dump}

\subsubsection{Rehabilitation design requirements}

Development of the rehabilitation design for the NEBC waste dump at Tom Price operations presented a number of challenges. The dump itself is irregular in shape, having been constructed in a batter and berm configuration, but without standard lift heights or berm widths. The dump is also footprint constrained, with the area available for reshaping activities limited on the northern side by two permanent explosives magazine structures, on the east by a high voltage powerline/access road, and on the southwest by the current site's inert rubbish landfill. For these footprint reasons, it was identified that it would be necessary to utilise the least conservative design criteria permitted for Tom Price operations by Rio Tinto's current landform design tool, specifically $20 \mathrm{~m}$ high lifts with $20^{\circ}$ slopes and $10 \mathrm{~m}$ wide berms (minimum). Previous landform erosion modelling has indicated that these parameters are only suitable for dumps constructed from low erodibility waste, such as banded iron formation (BIF) waste types. The waste existing on the outside of the NEBC dump is known to have high erodibility, and the waste sources considered for encapsulating the dump ranged from high to medium erodibility. For this reason, it was identified that it would be necessary to armour the final batter surfaces with low erodibility waste to provide long-term surface stability.

Independent modelling was carried out by a consultant to determine the depth of armouring material that would be required on the final slopes to ensure surface stability over the longer term. Specifically, water erosion prediction project (WEPP) runoff and erosion modelling for specified batter profile heights, using a 100-year climate sequence specific to Tom Price, was carried out using waste data generated from previous sampling and testing of Pilbara waste types. It was concluded that a minimum depth of $0.4 \mathrm{~m}$ of armouring material was required for $20 \mathrm{~m}$ slope heights but that $0.5 \mathrm{~m}$ was preferable to account for the variability that may be encountered during material spreading. This requirement was integrated into the NEBC rehabilitation design. 


\subsubsection{Cover system net percolation and salt update modelling to determine depth of cover}

The second aspect of the rehabilitation design was the encapsulation of the buried black shale waste within the dump. As the exact location of the PAF black shale material within the dump could not be determined with confidence, a conservative approach to waste dump rehabilitation was adopted. The rehabilitation design required the reshaping of the dump followed by the encapsulation of all surfaces (batters and berms) with inert waste to ensure that any PAF black shale material that may be near to surface is adequately covered.

The current Rio Tinto approach for managing PAF material at Tom Price operations is to add $5 \mathrm{~m}$ of inert waste above any surface containing black shale (Green 2009). This requirement was incorporated into the rehabilitation design, resulting in $5 \mathrm{~m}$ of clean fill being proposed for placement on the berms, and $4.5 \mathrm{~m}$ of clean fill on the sloped batter faces followed by $0.5 \mathrm{~m}$ of armouring material (total $5 \mathrm{~m}$ ).

The exception to this was the $815 \mathrm{RL}$, which was considered to be adequately encapsulated based on previous drill results and the $832 \mathrm{RL}$, which was considered to require only $2 \mathrm{~m}$ of additional waste to complete the store and release cover.

A number of different cover thickness scenarios were modelled to determine the impact on dump oxidation rates, net percolation, erosion and salt accumulation. The sulphate generation rate for an uncovered dump can be significantly reduced through the application of a cover and varying thicknesses were investigated. Likewise, the net percolation can be decreased through different combinations of cover material and thickness. All scenarios were reviewed and optimised to determine an acceptable cover thickness that does not compromise AMD generation. Preliminary results suggest that the total depth of cover proposed for placement on the NEBC waste dump may be reduced, however, this investigative work is still ongoing.

\subsubsection{Final rehabilitation design for North End Box Cut waste dump}

Based on the information outlined in Section 2.2.1 and Section 2.2.2, a rehabilitation design for the NEBC waste dump was generated (Figure 4). This design requires the following major steps:

- Reshaping of the entire landform, including the previously rehabilitated areas, to achieve a stable landform conforming to the guide of $20^{\circ}$ slopes, $20 \mathrm{~m}$ high lifts and $10 \mathrm{~m}$ wide berms (minimum) with an $11^{\circ}$ back slope. Some limited areas where lift heights exceed $20 \mathrm{~m}$ will have a minor concave section constructed at the toe.

- Placement of a 5 m layer of inert fill over all slopes and berms (except the $815 \mathrm{RL}$ and $832 \mathrm{RL}$ ) to encapsulate any underlying black shale material. This includes a $0.5 \mathrm{~m}$ layer of rocky BIF waste on the batter faces to reduce erosion.

- Placement of $2 \mathrm{~m}$ of compacted, inert shale waste on the $832 \mathrm{RL}$ to complete the existing store and release cover.

The total material movement required to implement the NEBC rehabilitation design are outlined in Table 1. The final design meets the requirements of internal Rio Tinto guidance for the management of PAF black shale material and for landform design. The decision to shape the dump prior to application of the encapsulation layer was based on an assessment of volumes to encapsulate with and without initial shaping. The volumetric savings of encapsulation material was significant.

At the time of writing this paper, final results on the net percolation and salt uptake modelling were still pending. Should the modelling results support a reduction in the depth of the encapsulating cover from $4.5 \mathrm{~m}$ on the batter faces and $5 \mathrm{~m}$ on the berms to $2.5 \mathrm{~m}$ and $3 \mathrm{~m}$, respectively, as is anticipated, a $>40 \%$ reduction in material movements will be realised for this component of the design. 
Table 1 Material movements required for the implementation of the North End Box Cut waste dump rehabilitation design

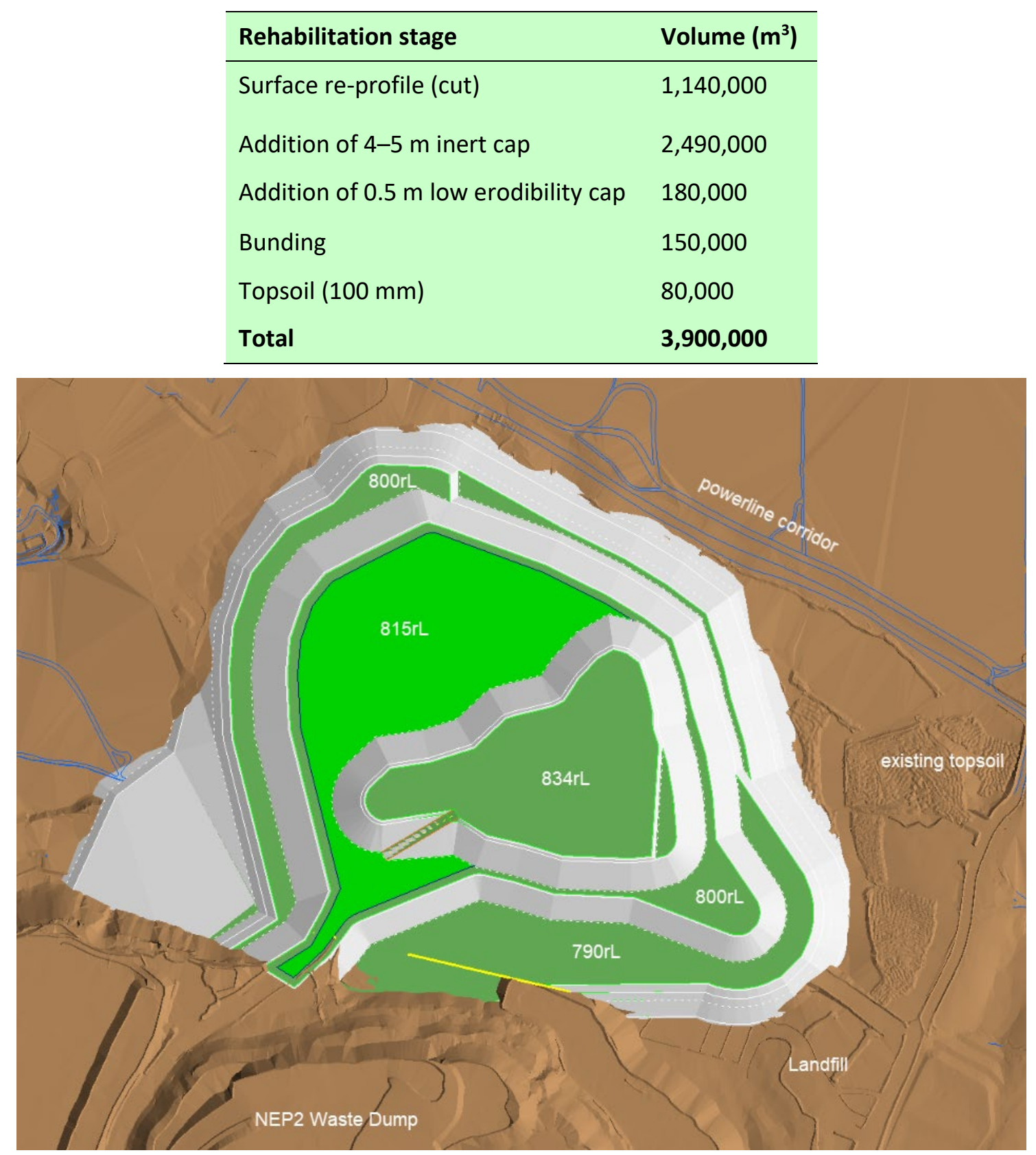

Figure 4 Final landform design for NEBC waste dump at Tom Price operations (post rehabilitation)

\subsection{Integration of rehabilitation requirements with the site mine plan}

The volume of clean fill required to meet the rehabilitation design requirements is significant (ca. $2.5 \mathrm{M} \mathrm{m}^{3}$ ). During project planning, two options for sourcing this waste were identified:

1. Scenario 1: Engage a contractor to load/haul the material from an existing waste dump.

2. Scenario 2: Redirect pre-strip waste from a nearby pit to the NEBC waste dump for use in the rehabilitation project.

Discussions with the Tom Price life-of-mine planning, site technical services and operational management teams were carried out throughout 2017 and 2018 to determine what opportunities may exist to implement Scenario 2. It was identified that the nearby NX14 pit was due for development in 2019 and waste was 
scheduled to be deposited nearby to the NEBC waste dump throughout 2019-2020. Redirection of all the NX14 waste to the top of the NEBC waste dump was calculated to require an additional 700 truck hours in 2019. The total cost saving of this option, compared to Scenario 1 above, is estimated at AUD 2 million in 2019 alone, with further savings realised throughout the course of the project. This approach was supported by Tom Price operations and the waste movements from the NX14 pit to the NEBC waste dump were subsequently placed into the 2019 site mine plan.

Waste movements from NX14 pit are scheduled to continue until the last quarter of 2020, however the pit is expected to have insufficient waste to meet the full rehabilitation requirement of the NEBC waste dump. This shortfall will be addressed when a second nearby pit commences development in 2021.

If all waste required for the rehabilitation of NEBC waste dump is able to be sourced directly ex-pit and costed to the project as operational over-haul, the total cost savings have the potential to exceed AUD six million.

\section{Conclusion}

Rehabilitation of the NEBC waste dump at Tom Price is expected to commence in 2019, with initial preparatory earthworks having been completed in the last quarter of 2018. The rehabilitation of the waste dump requires the movement of significant volumes of clean, inert waste to ensure the adequate encapsulation of PAF black shale material buried within the waste dump. Several studies have been undertaken to determine net percolation, salt accumulation, changes to oxidation rates and erosion potential from different material types and cover thickness scenarios. This enables appropriate long-term management of risk and a design that optimises the use of available waste material.

The integration of mine waste movements for rehabilitation into the site mine plan has resulted in the ability to haul waste directly from a new pit development to the waste dump. This has offered significant cost savings for Rio Tinto, while minimising the company's closure liabilities.

\section{Acknowledgement}

Many thanks to Rhys Sutton (Rio Tinto), who completed some of the early work focused on identifying PAF locations in the NEBC dump.

\section{References}

Green, R 2009, 'Holistic management of sulphides at Rio Tinto Iron Ore's Pilbara mine sites', Mining Technology, vol. 118, pp. 232-237.

Green, R 2012, 'Geochemical assessment of mineral waste through the mine life cycle', in CD McCullough, MA Lund \& L Wyse (eds), Proceedings of the International Mine Water Association Symposium, International Mine Water Association. pp. 467-471.

Shurniak, RE, O'Kane, MA \& Green, R 2012, 'Simulation of Seven Years of Field Performance Monitoring at Rio Tinto Iron Ore, Mount Tom Price Mine using Soil-Plant-Atmosphere Numerical Modelling', in AB Fourie \& M Tibbett (eds), Proceedings of the Seventh International Conference on Mine Closure, Australian Centre for Geomechanics, Perth, pp. 393-405. 